\title{
Reduced dry olive residue phytotoxicity in the field by the combination of physical and biological treatments
}

\author{
E. Aranda ${ }^{1}$, I. Sampedro ${ }^{1}$, M. García-Sanchez ${ }^{1}$, R. Reina ${ }^{1}$, C. Arriagada ${ }^{2}$, J.A. Ocampo ${ }^{1}$, \\ I. García-Romera ${ }^{1 *}$ \\ ${ }^{1}$ Departmento de Microbiología del Suelo y Sistemas Simbióticos, Estación Experimental del Zaidín, CSIC, \\ Prof. Albareda 1, Apdo. 419, 18008 Granada, Spain. ${ }^{2}$ Departamento de Ciencias Forestales, Universidad de La \\ Frontera. Casilla 54-D, Temuco, Chile Corresponding author: inmaculada.garcia@eez.csic.es
}

\begin{abstract}
Olive oil extraction generates large amounts of olive mill residues (DOR) which may be used as organic fertilizer. The influence of a combination of physical fractionation and saprobe fungal incubation on the phytotoxicity of DOR was studied. The physical fractions of DOR, obtained following extraction using ethyl acetate (EDOR) and water (ADOR) were less phytotoxic than DOR with respect to the shoot dry weight of tomato. There was no relationship between the total phenol content of the different DOR physical fractions and their phytotoxicity. The saprophytic fungus Coriolopsis rigida reduced DOR and ADOR phytotoxicity and eliminated the phytotoxicity of EDOR. However, unlike the physical treatments of DOR, the decrease in the phenol content of EDOR and ADOR caused by $C$. rigida was closely paralleled to the decrease in their phytotoxicity. After 30 days of incubation, C. rigida was able to eliminate the phytotoxicity of EDOR on tomato plants grown in the field.
\end{abstract}

Keywords: Olive mill waste, ethyl acetate, organic fertilizer, phenols, saprophytic fungi, Solanum lycopersicum. 


\section{Introduction}

The olive oil production by a two-phase extraction system generates a semi-solid organic waste which has a great potential as fertilizer due to high content in organic and inorganic nutrient (Alburquerque et al., 2004). However, olive mill dry residue (DOR) contains phytotoxic components, mainly phenols, which are capable of inhibiting plant growth (Martín et al., 2002). Considerable efforts to decrease the phytotoxicity of DOR using biological, chemical and physical treatment methods have been made (Ginos et al., 2006; Aranda et al., 2006; Sampedro et al., 2008). Nevertheless, none of these approaches, on their own, constitute a comprehensive solution to the problem of reducing phytotoxic compounds (Cermola et al., 2004). However, by combining the physical and biological treatments, it may be possible to use DOR as an organic amendment in agricultural soil (Aranda et al., 2010). On the other hand, most of the experiments developed to study the use of olive residues as organic fertilizers were carried out in greenhouses rather than under field conditions.

The aim of this study is to analyse the reduction in the phytotoxicity of DOR through a physical treatment, which combines its ethyl acetate and water fractions, with a biological treatment by the saprophytic fungus Coriolopsis rigida under field conditions.

\section{Material and methods}

\section{Sample preparation}

Dry olive residue (DOR), a solid residue obtained after chemical residual oil extraction with hexane, was provided from an olive oil manufacturer. The main characteristic of DOR was determined by Sampedro et al., (2008). Ethyl acetate (EDOR) and aqueous (ADOR) extracts from DOR were obtained using Sox- hlet extraction with ethyl acetate and water, respectively, in a 1:4 $(\mathrm{w} / \mathrm{v})$ ratio for $16 \mathrm{~h}$. The main chemical characteristics of EDOR and ADOR were determined by Aranda et al., 2006 and Sampedro et al., 2012 respectively. The EDOR and ADOR liquid extracts were evaporated to dryness, and the residue was resuspended in water in similar initial ratio. The inoculum of Coriolopsis rigida (CECT 20449) was prepared by the methods of Aranda et al., (2009). Each residue was inoculated with $0.45 \mathrm{~g} \mathrm{~L}^{-1}$ of the fungus. Sterilized DOR was incubated with the fungus statically for 20 weeks at $28{ }^{\circ} \mathrm{C}$. The fungus was also grown in Czapek medium with $50 \%$ of EDOR and ADOR for 30 days at $28^{\circ} \mathrm{C}$ at $125 \mathrm{rpm}$ and the culture liquid was separated from the mycelium by centrifugation ( 8000 g). Sterilized DOR, EDOR and ADOR inoculated or not (control) with the saprobe fungi were use for the phytotoxicity experiment.

The total phenolic contents of DOR, EDOR and ADOR were estimated according to Ribereau-Gayon (1968), using tannic acid as a standard and were expressed as $\mathrm{g} \mathrm{kg}^{-1}$ of residue.

\section{Greenhouse experiment}

The phytotoxicity experiments were carried out in pots containing $300 \mathrm{~g}$ of soil obtained from the Estación Experimental del Zaidín (EEZ) (Granada, Spain), which was steam-sterilized and mixed with sterilized quartz sand (1:1 volume). The main characteristic of the soil was described by Sampedro et al., 2008. Steam-sterilized DOR, ADOR and EDOR incubated with and without $C$. rigida, as described previously, were applied to the pots of soil in 50 ton $\mathrm{ha}^{-1}$ concentrations, a dosage recommended for farmyard manure applications. Pots without residue applications were also used. Tomato (Solanum lycopersicum L.) was 
used as the test plant. The plants (one per pot) were grown in a greenhouse under controlled conditions, were watered from below, and were fed weekly with a $10 \mathrm{ml}$ nutrient solution (Hewitt, 1966). They were harvested after 5 weeks and shoot weight was then determined. The experiment was carried out with four repetitions of each treatment.

\section{Field experiment}

For the field experiments, plants were grown in greenhouse under conditions similar to those described previously. After 4 weeks, they were transferred from the pots to $40 \mathrm{x} 40 \mathrm{~cm}$ plots separated by $1.5-\mathrm{m}$ borders in the EEZ field. Steam-sterilized DOR and EDOR incubated with and without $C$. rigida, as described previously, were applied to the plots in 0 , and 50 ton ha ${ }^{-1}$ concentrations. Four replicate plots containing 6 plants per plot were randomly selected for each treatment. The plants were harvested after 10 weeks, and shoot and fruit dry matter levels were measured.

The data obtained was subjected to analysis of variance (ANOVA). The mean values of four replicates were compared using the standard error of the mean and the Tukey test $(p=0.05)$.

\section{Results and discussion}

The physical pre-treatments of olive residues considerably reduced their phytotoxicity levels (Ginos et al., 2006; Aranda et al., 2009). The EDOR and ADOR fractions had less phytotoxic impact on the shoot dry weight of tomato than DOR (Table 1). Phenols have been reported as the main cause of phytotoxicity in olive residues (Linares et al., 2003). The phenol content of DOR, EDOR and ADOR were $27.5 \pm 1.3,6.6 \pm 0.2$ and $17.4 \pm 0.7 \mathrm{~g}$ phenol $\mathrm{kg}^{-1}$ of DOR, respectively. Although, these results may suggest that phenols were responsible of the phyto- toxicity of these residues, the similar phytotoxicity levels found in the ADOR and EDOR fractions, despite their differing phenol content levels, indicate that the role played by phenols in phytotoxicity is unclear. It has previously been observed that there is no relationship between the monomeric phenol content of different physical fractions of DOR and their phytotoxicity (Aranda et al., 2007). It has also been reported that some phenols inhibit plant growth regardless of their concentrations, while others were affected by mutual synergistic inhibition (Della Greca et al., 2001).

The biological treatment of the physical fractions of different olive residues has been deemed necessary in order to enhance phytotoxicity reduction and elimination as well as plant growth (Aranda et al., 2009). C. rigida eliminated EDOR phytotoxicity and reduced its levels in DOR and ADOR. The decrease in olive residue phenols caused by saprophytic fungi has been suggested as the main mechanism through which these fungi reduced the phytotoxicity of the residues (Aranda et al., 2006). C. rigida reduced the phenol content of DOR, EDOR and ADOR to $13.7 \pm 0.5,1.3 \pm 0.06$ and $3.74 \pm 0.1$ phenol $\mathrm{kg}^{-1}$ of DOR, respectively. Unlike the physical treatments of the dry mill residues, the decrease in the phenol content of DOR, EDOR and ADOR caused by C. rigida was closely paralleled to the decrease in their phytotoxicity (Table 1). These results suggest that the biological treatments of DOR through the application of $C$. rigida have different phytotoxicity reduction mechanisms from those of the physical treatments. It is known that $C$. rigida is capable of transforming certain phytotoxic monomeric phenols into non-phytotoxic polymeric phenols from the DOR (Casa et al., 2003). The degree of polymerisation of these phenols may limit the accessibility via plant cell membrane, thus avoiding phytotoxicity (Sampedro et al., 2005). 
Table 1. Shoot dry weight of tomato (Solanum lycopersicum $\mathrm{L}$ ) grown in presence of dry olive mill residue (DOR), ethyl acetate extract of DOR (EDOR) and aqueous extract of DOR (ADOR), incubated with Coriolopsis rigida.

\begin{tabular}{lcc}
\hline Residue & Treatments & $\begin{array}{c}\text { Shoot dry } \\
\text { weight (mg) }\end{array}$ \\
\hline No residue & & $405.6 \mathrm{~d}$ \\
DOR & Control & $24.7 \mathrm{a}$ \\
& C. rigida & $102.3 \mathrm{~b}$ \\
EDOR & Control & $112.4 \mathrm{~b}$ \\
& C. rigida & $385.7 \mathrm{~d}$ \\
ADOR & Control & $98.7 \mathrm{~b}$ \\
& C. rigida & $152.2 \mathrm{c}$ \\
\hline
\end{tabular}

The shoot and the fruit weight of tomato plants fell when grown in plots with DOR, EDOR and ADOR additions (Table 2). Similar trends in the phytotoxic effects of DOR, EDOR and ADOR were observed in both plots and pots. However, plants grown in the presence of EDOR incubated with C. rigida had similar shoot and fruit weights to those for plants grown in the absence of residues (Table 2).

Table 2. Shoot and fruit dry weights of tomato (Solanum lycopersicum L) grown in field plots in presence of dry olive mill residue (DOR), ethyl acetate extract of DOR (EDOR) and aqueous extract of DOR (ADOR), incubated with Coriolopsis rigida.

\begin{tabular}{lccc}
\hline Residue & Treatments & Shoot weight $(\mathbf{g})$ & Fruit weight $(\mathbf{g})$ \\
\hline No residue & & $110.3 \mathrm{~d}$ & $1327.3 \mathrm{~d}$ \\
DOR & Not inoculated & $18.4 \mathrm{a}$ & $395.8 \mathrm{a}$ \\
& C. rigida & $69.2 \mathrm{c}$ & $872.6 \mathrm{c}$ \\
EDOR & Not inoculated & $29.7 \mathrm{ab}$ & $606.5 \mathrm{~b}$ \\
& C. rigida & $95.4 \mathrm{~d}$ & $1298.4 \mathrm{~d}$ \\
ADOR & Not inoculated & $25.3 \mathrm{ab}$ & $587.1 \mathrm{~b}$ \\
& C. rigida & $77.1 \mathrm{c}$ & $753.2 \mathrm{c}$ \\
\hline
\end{tabular}

Data are the mean of the shoot dry weight of tomato plants at the end of the experiments. Column values followed by similar letters are not significantly different, as determined by Tukey's multiple range test at level $p=0.05$.

It has been previously reported that the fungus $C$. rigida takes 20 weeks to reduce the phytotoxicity of DOR (Sampedro et al., 2005). However we found that C. rigida was capable of reducing or eliminating the phytotoxicity of the ethyl acetate and water fractions of DOR after 30 days of incubation. This would suggest that the combination of physical and biological treatments reduce the time necessary to eliminate the phytotoxicity of olive residues, therefore the use of this agrowaste as organic amendment in agricultural soil may be possible.

\section{CONCLUSIONS}

The olive residue used as fertilizer must be treated through a biological treatment before being applied, in order to reduce toxicity in plant production. We demonstrated in this work, that the combination of a physical ethyl acetate fractionation of dry olive residue (DOR) and a biological treatment involving incubation during 30 days with the saprophytic fungus $C$. rigida eliminates its phytotoxic effect on tomato plant growth in fields. 


\section{Acknowledgements}

Financial support for this study was provided by the Junta de Andalucía (PO6-AGR-01906) and the Science and Innovation Ministry (AGL2008-00572).

\section{References}

Alburquerque, J.A., Gonzálvez, J., García, D., Cegarra, J. 2004. Agrochemical characterisation of "alperujo", a solid by-product of the two-phase centrifugation method for olive oil extraction. Biores. Technol. 91, 195-200.

Aranda, E., García-Romera, I., Ocampo, J.A., Carbone, V., Malorni, A., Sannino, F., Capasso, R. 2007. Chemical characterization and effects on Lepidium sativum of the native and bioremediated components of dry olive mil residue. Chemosphere. 3, 229-239.

Aranda, E., Sampedro, I., Díaz, R., García, M., Arriagada, C., Ocampo, J.A., García-Romera, I. 2009. The effects of the arbuscular mycorrhizal fungus Glomus deserticola on growth of tomato plants grown in the presence of olive mill residues modified by treatments with saprophytic fungi. Symbiosis. 47, 133-140.

Aranda, E., Sampedro, I., Ocampo, J.A., García-Romera, I. 2006. Phenolic removal of olive-mill dry residues by laccase activity of white-rot fungi and its impact on tomato plant growth. Int. Biodeter. Biodegr. 58, 176-79.

Casa, R., D’Annibale, A., Pieruccetti, F., Stazi, S.R., Sermanni, G.G., Lo Cascio, B. 2003. Reduction of the phenolic components in olive-mill wastewater by an enzymatic treatment and its impact on durum wheat (Triticum durum Desf.) germinability. Chemosphere. 50, 959-966.

Cermola, F., DellaGreca, M., Iesce, M.R., Montella, S., Pollio, A., Temussi, F. 2004. A mild photochemical approach to the degradation of phenols from olive oil mill wastewater. Chemosphere. 55, 1035-1041.
Della Greca, M., Monaco, P., Pinto, G., Pollio, A., Previtera, L., Temussi, F. 2001. Phytotoxicity of low molecular-weight phenols from olive mill wastewaters. Bull. Environ. Contam. Toxicol. 67, 352-359.

Ginos, A., Manios, T., Mantzavinos, D. 2006. Treatment of olive mill effluent by coagulation-flocculation-hydrogen peroxide oxidation and effect on phytotoxicity. J. Hazard. Mater. 133, 135-142.

Hewitt, E.J. 1966. Sand water culture methods used in the study of plant nutrition. CAB, Tech. Co., Farmham Royal, Bucks, UK, No. 22.

Linares, A., Caba, J.M., Ligero, F., De La Rubia, T., Martínez, J. 2003. Detoxification of semisolid olive-mill wastes and pine-chip mixtures using Phanerochaete flavido-alba. Chemosphere. 51, 887-891.

Martín, J., Sampedro, I., García-Romera, I., GarcíaGarrido, J.M., Ocampo, J.A. 2002. Arbuscular mycorrhizal colonization and growth of soybean (Glycine max) and lettuce (Lactuca sativa) and phytotoxic effects of olive mill residues. Soil Biol. Biochem. 34, 1769-1775.

Ribereau-Gayon, P. 1968. Les Composes Phenoliques des Vegetaux. Dumond, Paris.

Sampedro, I., Aranda, R., Díaz, R., García-Sánchez, J.A. Ocampo, I., García-Romera, I. 2008. Saprobe fungi decreased the sensitivity to the toxic effect of dry olive mill residue on arbuscular mycorrhizal plants. Chemosphere. 70, 1383-1389.

Sampedro, I., D’Annibale, A., Federici, F., GarcíaRomera, I., Siles, J.A., Petruccioli, M. 2012. Nonsupplemented aqueous extract from dry olive mill residue: A possible medium for fungal manganese peroxidase production. Biochem. Eng. J. http:// dx.doi.org/10.1016/j.bej.2012.03.011.

Sampedro, I., Ocampo, J.A., García-Romera, I., D'Annibale, A. 2005. Bioconversion of olive mill dry residue by $F$. lateritium and subsequent impact on its phytotoxicity. Chemosphere. 60, 13931400 . 
